
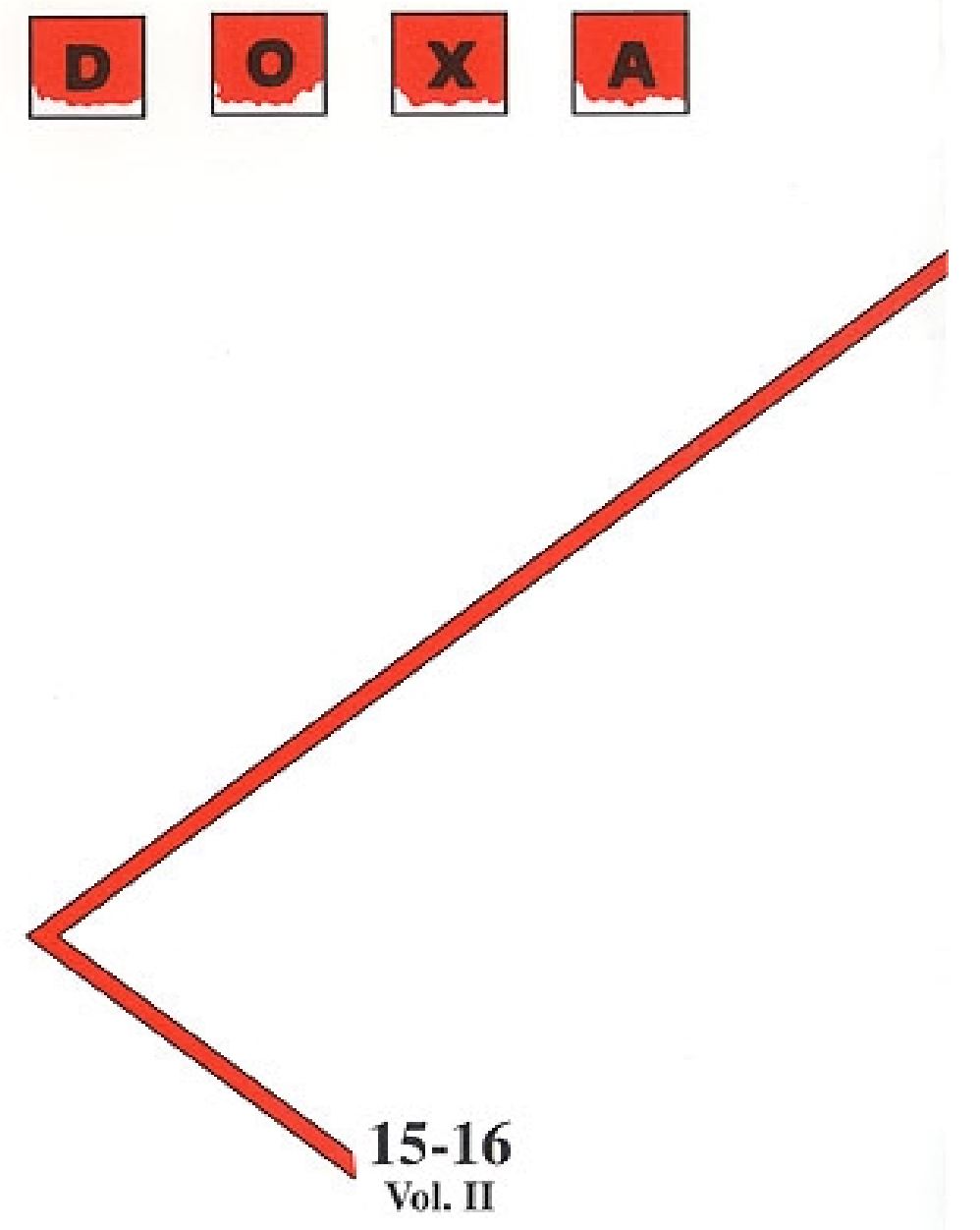

CUADERNOS DE FILOSOFIA Y DERECHO 
\begin{tabular}{llll}
\hline DERECHO, MORAL & Y & POLÍTICA
\end{tabular} 


\section{DERECHO, MORAL Y POLÍTICA: TENSIONES CENTRÍPETAS Y CENTRÍFUGAS}

\section{Derecho, Moral y Política: entre la separación y la unidad}

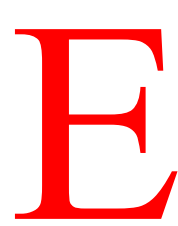

$\mathrm{n}$ algunas de las teorías jurídicas más difundidas de la actualidad (Kelsen, Hart, Ross, Bobbio...) parece un hecho establecido que Derecho, Moral, y Política son sistemas normativos distintos que, a su vez, engendran saberes diferenciados. Constituye un mérito de esas construcciones teóricas el haber propiciado, con arduo afán metodológico y depurados instrumentos conceptuales, una segmentación de los tres grandes sistemas normativos que rigen la conducta práctica. Esos empeños doctrinales han pretendido discernir con justeza, desde premisas y con resultados divergentes, la peculiaridad de lo jurídico, separándolo de otras esferas del obrar humano e intentando acotar en su seno demarcaciones y áreas.

No estimo aventurado conjeturar que en la cultura jurídica contemporánea exista una coincidencia generalizada en considerar que Derecho, Moral y Política, son realidades normativas peculiares y distintas. Si bien, lo mismo teóricos del Derecho que operadores jurídicos discrepan, con pareja unanimidad, de los presupuestos y fundamentos que sirven de soporte explicativo a esa diferenciación. Y retorna una amplia coincidencia en lo que atañe en los rasgos básicos desde los que se delimitan conceptualmente cada una de estas tres esferas. Así, se caracteriza, en forma mayoritaria, a la Moral como un conjunto de reglas de comportamiento que definen la actuación correcta (buena) en una determinada sociedad (Moral social o positiva), bien como los dictados orientadores de la conducta (buena) procedentes de la conciencia autónoma individual (Moral crítica). El Derecho viene mayoritariamente entendido como el conjunto de normas de inexorable cumplimiento que prescriben un orden en la coexistencia. Y la política aparece como el conjunto de reglas que se consideran eficaces para obtener, ejercer y conservar el poder. 
No obstante, cuando se traspasan los linderos de las delimitaciones teóricas y se penetra en el espacio más complejo y umbrío de la experiencia jurídica, esos límites precisos se relativizan y comienzan a devenir sinuosos; hasta opacos. Para comprobarlo puede ser útil recurrir a una sentencia de nuestro Tribunal Constitucional. Se trata del denominado caso del «Cura de Hío». En este supuesto se admitió la demanda del diario «El País», y se anularon las sentencias condenatorias del Tribunal Supremo y de la Audiencia Territorial de Madrid. Esa condena se basaba en la falsedad de unos titulares de dicho periódico en los que se afirmaba: «un cura de Cangas de Morrazo inicia la cruzada contra los desnudistas gallegos»; y añadía: «garrote en mano el sacerdote lanzó al vecindario contra un campamento autorizado». Pudo demostrarse en función de los hechos que el cura de referencia no era de Cangas de Morrazo, sino de Hío; que jamás había incitado a los vecinos de dicha localidad a realizar ningún tipo de actuación contra los nudistas; y que tampoco había empuñado ningún garrote. No obstante, según la sorprendente interpretación del Tribunal Constitucional la falsedad de estas imputaciones no tenía porqué privarlas de la protección constitucional. La inveracidad o inexactitud de una información, como consecuencia de un error de identificación, no tiene trascendencia suficiente «como para entender quebrantado su carácter de información veraz» (STC 240/1992, FJ 6). La argumentación del Tribunal Constitucional se remite a su propia jurisprudencia para legitimar el carácter prevalente de la libertad de información sobre el derecho al honor, por la significación que aquella posee de «garantía institucional de una opinión pública indisolublemente unida al pluralismo político dentro de un Estado democrático» (FJ 3).

Causa estupor, desde el punto de vista de la corrección argumental la tesis sustentada por el máximo interpreta de la Constitución. Esta tesis debe ser contemplada con serias reservas. Una cosa son las argumentaciones normativas sobre la racionalidad o legitimidad de los supuestos que permiten que la información prevalezca sobre la intimidad, en los que el Tribunal tiene un amplio margen de discrecionalidad valorativa; y otra muy distinta es el juzgar sobre la verdad o falsedad, la exactitud o inexactitud de determinados hechos que debe ser realizada en función de comprobaciones empíricas y en las que el Tribunal debe operar con estrictos criterios descriptivos.

Pero dejando a un lado estas observaciones sobre los aspectos formales de la decisión, en lo que afecta a los criterios materiales que en ella se contienen se puede advertir:

a) Que existen determinados valores morales como el honor (reputado en el célebre motto calderoniano como «patrimonio del 
alma») que informan el contenido de derechos fundamentales y, que por tanto, son objeto de tutela jurídica.

b) Que el Derecho se hace cargo también de exigencias políticas, como la de la garantía de la opinión pública, indisolublemente unida al pluralismo político dentro de un Estado democrático.

c) Que razones políticas pueden prevalecer, en lo que a la tutela jurídica se refiere, sobre determinados valores morales. Si bien, en el caso que aquí nos sirve de referencia, pudiera también interpretarse como un conflicto entre valores morales: de una parte el pluralismo propio de las sociedades democráticas como valor de la moralidad positiva y de otra la defensa del honor como expresión de la moral individual.

\section{La venganza de los olvidos: el ethos social}

La experiencia jurídica parece resistirse a los intentos teóricos tendentes a independizar cada uno de los sectores normativos de la conducta práctica. Por depurados que puedan parecer los marcos conceptuales dirigidos a clarificar la separación: por elaborados que sean las actiones finiun regundorun demarcadoras de sus respectivos ámbitos, la experiencia jurídica parece empeñada en recordar y religar la unidad originaria de la conducta práctica. La célebre clasificación de cuño aristotélico distingue entre los saberes teoréticos, propios de las virtudes dianoéticas que guían el intelecto y los prácticos que se dirigen a conseguir el ideal de la felicidad, es decir, la «vida buena» de los miembros de la comunidad (Metafísica, E, 1, 1025b 20-22; Política, I, 2, 1252b). A su vez, en el seno de las virtudes prácticas traza una distinción entre las éticas, las políticas y las económicas, siendo la justicia la virtud ética por excelencia, aquella que compendia todas las restantes virtudes (Ética a Nicómaco, V. I, 11 29a).

El planteamiento aristotélico refleja con nitidez la unidad de la experiencia práctica común a todas las formaciones sociales del mundo antiguo así como a las comunidades primitivas, en las que las fronteras de demarcación entre lo moral, lo político y lo jurídico son sinuosas y confusas. En los pueblos antiguos existe un acervo compartido de creencias y tradiciones de carácter mágico, religioso, moral, político y jurídico. Ese conglomerado normativo expresa el ethos social del grupo y define lo que debe o no debe hacerse (los tabúes) de la sociedad. En las sociedades primitivas la vida social integra un conjunto de funciones cada una de las cuales se apoya en las demás y la supone. La experiencia práctica es la vida integral de la comunidad y sólo mediante proyecciones de categorías conceptuales y metodológicas propias de nuestra experiencia, pero ajenas a 
esas culturas, es posible distinguir líneas divisorias. El progreso de las ciencias sociales ha consistido en buena parte en su contribución a dibujar un cosmos de demarcaciones y áreas acotadas en lo que antes era un caos primitivo de normatividades difusas y confusas. Pero la unidad de la experiencia social humana se resiste a esa parcelación de sus reglamentaciones y denuncia las premisas ilusorias en las que, muchas veces, se sustentan. Frente a cualquier intento de ignorarlo u olvidarlo el ethos emerge cíclicamente en sucesivos momentos de la evolución cultural.

Es probable que el empeño moderno más notorio por reivindicar la indispensabilidad del ethos se deba a Hegel. En la eticidad, a tenor de una enseñanza de Hegel plena de vigencia, la libertad subjetiva se afirma como un bien viviente (lebendige Gute) que se realiza en las instituciones sociales. La Sittlichkeit supone la síntesis superadora de la dimensión formal y abstracta del Derecho y el carácter ideal de la Moral; en ella el hombre se realiza plenamente como realidad concreta (Grundlinien der Philosophie des Rechts, $\S \S$ 142 y 144-145). Desde sus trabajos juveniles, en los que concibe la polis griega como sittliches Gemeinwesen, Hegel sustituye los planteamientos tradicionales de la teoría jurídica, moral y política centrados en la actividad del hombre individual y aislado, por un enfoque comunitario. El centro de gravedad se transfiere desde el individuo abstracto al hombre concreto que se integra en una colectividad orgánica e histórica: el pueblo. El espíritu popular (Volksgeist) compendia la religión, el arte, las costumbres, el Derecho y, en suma, el ethos de un pueblo.

Es cierto que en la doctrina hegeliana subyace el peligro del Estado ético, de aquella forma política en la que los individuos pierden su autonomía y sus libertades, que quedan absorbidas por el valor absoluto que encarna el propio Estado. El hecho de que ese Estado sea concebido como síntesis de lo particular y lo universal y como realización perfecta de lo individual en el absoluto, no impide que pueda degenerar en lo que, certeramente, fue calificado como Estado de fuerza (Machtsstaat ). Pero no es menos evidente, que la investigación hegeliana, la Hegel-Forschung, de estas últimas décadas hace difícil mantener una interpretación que le convertía en legitimador del absolutismo e inspirador de la ideología nazi (Cfr. Pérez Luño, 1991b, 102 ss. con orientaciones bibliográficas).

La Sittlichkeit hegeliana supuso una renovación de la ética institucional, cuya tradición arranca de la Política aristotélica. Su aportación principal se cifra en haber superado la fractura entre una moralidad subjetiva ideal y una moral social institucionalizada, a que respondía la concepción del ethos en la filosofía práctica aristotélica. Porque para Hegel la moralidad subjetiva, deviene eticidad, es decir, adquiere concreción histórica a través de su realización en las instituciones 
sociales jurídicas y políticas (Habermas, 1992, 64 ss y 541 ss).

La historia de la filosofía práctica ha consistido básicamente en una especie de flujo y reflujo en que se han sucedido intentos centrífugos (analíticos, conceptualistas o metodológicos) dirigidos a establecer demarcaciones claras y precisas entre el Derecho, la Moral y la Política, y en empeños centrípetos (historicistas y vitalistas) tendentes a recobrar la unidad radical originaria del ethos y la consiguiente interdependencia de los sectores normativos que lo integran.

\section{Dos fragmentos de historia:}

Los confines actuales entre el Derecho, la Moral y la Política no constituyen un dato inalterable, sino el resultado de incesantes fluctuaciones. Por eso, toda indagación sobre las relaciones que se dan en el presente entre estos sectores normativos debe contar, aunque sea en forma sumaria y esquemática, con el desarrollo histórico de la cuestión.

Para los orígenes de la distinción entre Derecho, Moral y Política vale lo que, con mal disimulada ironía, recuerda Ortega respecto de cierto libro de Derecho Romano que sirvió de texto en una Universidad española, y en el que se abordaba el sistema tributario romano. Al iniciar dicho Capítulo indicaba ese texto: «los impuestos en Roma comenzaron por no existir» (Ortega y Gasset 1983, 6, 157). Pues eso mismo ocurre con la distinción entre Derecho, Moral y Política que era desconocida en todas las sociedades primitivas en las que rige un entramado normativo unitario y compacto que expresa el ethos de la comunidad. Esa normatividad determina las esferas de lo permitido, lo prohibido y lo debido por normas religiosas, morales, políticas y jurídicas, conjunta y simultáneamente. Conforme retrocedemos en la cronología de la historia y nos acercamos a la vida primitiva, las fronteras entre lo moral, lo jurídico y lo político se tornan más borrosas. La componente social y colectiva del ethos que dirige y absorbe, casi por completo, la individualidad domina bajo la forma de tradiciones establecidas la entera vida humana. En las formaciones sociales primitivas no se trata de perfilar los rasgos diferenciales -jurídicos, morales o políticos- de las conductas, sino de mantenerlas en la integridad omnicomprensiva y totalizadora del ethos. Será preciso llegar a la decantación reflexiva que implica la cultura clásica greco-romana para introducir pautas de distinción. A partir de entonces se asiste a tentativas cíclicas encaminadas a idear marcos de discernimiento racional de las diferencias $\mathrm{y}$ 
como contrapunto, a retornos que reclaman la vuelta a la disolución de todas las demarcaciones en la unidad colectiva del ethos.

Resulta muy ilustrativa la experiencia de los orígenes de esta cuestión en Grecia. Antes aún que en las teorías de los filósofos, las obras de los clásicos literarios helenos ofrecen noticia de las concepciones morales y jurídicas de un pueblo de pastores, que viven en constante guerra y que, a tenor de los poemas homéricos organiza su convivencia según la Themis. La idea de la justicia que expresa la noción de Themis es un compendio de normatividad sagrada, moral, política y jurídica, que se trasmite por oráculos de los dioses a los reyes y se impone a través de las themistes, es decir, un sistema de mandatos o tabúes, a los restantes miembros de la comunidad.

A partir del S. VIII a.C. nos da cuenta Hesíodo en Los trabajos y los días, que pertenece a una sociedad agrícola necesitada de paz y seguridad, el elogio de una nueva forma de justicia: Diké. Se trata de una normatividad que ha ido perdiendo su fundamento sacro para adquirir un carácter racional y que tiende a garantizar a los hombres la imparcialidad e igualdad de trato. Con Solón y Pericles, fundadores de la democracia ateniense en los siglos VI y V a.C., se refuerza el tránsito desde la concepción aristocrática de la justicia como Themis, a la democrática que se expresa en Diké. De forma todavía incierta se van perfilando las esferas diferenciadas de la Moral, con un incuestionable trasfondo religioso, y del Derecho, que ya no procede de oráculos inefables sólo asequibles a las clases aristocráticas, sino que se impone a quien ejerce el poder como un primer intento de supeditar la política a las leyes (Wolf, 1950, I, $125 \mathrm{ss}$ ).

La democracia tras su implantación en Atenas supuso, entre otros logros, un primer intento histórico por establecer ciertos límites entre Derecho, Moral y Política. Del ambiente cultural democrático fueron típicos exponentes los sofistas que a partir de la razón impulsaron la crítica de las instituciones conservadoras y aristocráticas, basadas en presupuestos religiosos y en la tradiciones. Su distinción entre fisis y nomos les servirá para delimitar las esferas de lo justo por naturaleza, o sea, lo que es conforme con una moral natural racional, y lo justo por ley, que responde a la contingencia de los intereses políticos. La disolución radical del ethos expresado por Themis, tuvo su principal protagonista en Critias, uno de los treinta tiranos, que gobernaron Atenas tras la victoria de Esparta (404 a.C.). En su drama satírico Sísifo concibe a la Moral y al Derecho como una invención humana dirigida a garantizar el orden social, y asimismo concibe la justicia (Diké) como el conjunto de leyes positivas garantizadas por la fuerza (Hybris) de quien detenta el poder político (Fassò, 1959).

Aristóteles, como se ha tenido ocasión de apuntar supra, supuso la culminación de este proceso. En su pensamiento se unen la tendencia 
centrípeta, manifestada en su esfuerzo por reconducir en la filosofía práctica la unidad normativa del Ethos; pero, al propio tiempo, su genio analítico le llevará a plantear con mayor nitidez que en cualquier pensador anterior la distinción conceptual centrífuga (que en él nunca supondrá fractura) entre Derecho, Moral y Política (Cfr. Ritter, 1970).

En el umbral de la historia de Roma se da la trabazón de las normatividades moral, jurídica y política que es propia de la génesis de todos los pueblos y culturas. También en Roma Derecho, Moral y Política aparecen como apéndices de los ritos sagrados dirigidos a averiguar la voluntad de los dioses. Esa voluntad divina constituye el fas, es decir lo permitido, aquello que no ofende a los dioses. Lo opuesto al fas era el nefas (el tabú), lo prohibido por contrario al ethos social del grupo, trasunto de sus creencias mágico-religiosas. En el proceso de secularización del fas surge el ius. como aquello que no lesiona a ningún hombre y que tiene su antítesis en la iniuria.

Ello no significa, en sus orígenes, que la expresión «ius» se halle desvinculada de connotaciones religiosas. Por el contrario, investigaciones actuales han venido a corroborar la tesis genialmente anticipada por Giambattista Vico (De uno, 11 y 145), quién hacía derivar el término «ius» de Iupiter y mostró la común raíz etimológica de «ious» y «iovis» (Cfr. Cruz, 1971, 16). No huelga tampoco olvidar que en el período arcaico lo mismo el fas que el ius venían interpretados, en régimen de monopolio, por el Colegio de los Pontífices. Los Pontífices ejercían indiferenciada y simultáneamente las funciones de guardianes de una normatividad global que abarcaba aspectos morales, jurídicos y políticos.

Las Doce Tablas representaron un hito básico en el proceso tendente a secularizar y racionalizar las fórmulas inicialmente religiosas conformadoras del primitivo ius. A partir del período clásico se adquiere conciencia de que el Derecho es algo independiente de las mores maiorum, es decir, del núcleo de costumbres morales y jurídicas que integraban el viejo ius del que eran oráculo los Pontífices. La máxima de Paulo a tenor de la cual el Derecho es aquello útil a los hombres ("pro utilitate hominum utile est» Digesto, 1, 1, 11), muestra un distanciamiento con las exigencias de la Moral. El propio Paulo afirmará tajantemente que no todo lo lícito es honesto «Non omne quod licet Honestum est» (Digesto, $50,17,144)$. Si bien, como reminiscencia del origen común del Derecho y la Moral, Celso mantendrá una definición de lo jurídico como un valor ético, al calificarlo de: «ars boni et aequi» (Digesto, 1, 1, 1). De igual modo, cuando Ulpiano establece los tres principios básicos del Derecho (tria praecepta iuris) incluye junto a una exigencia prioritariamente jurídica: dar a cada uno lo suyo (suum cuique tribuere), un postulado ético-jurídico: 
no dañar a nadie (alterum non laedere) y una máxima inequívocamente moral: vivir honestamente (honestum vivere) (Digesto, 1, 1, 10; Instituciones, 1, 1, 3).

Durante el período clásico el pretor, a través de sus edictos anuales y del recurso a la equidad (aequitas), realizó una función adaptadora del núcleo del ius civile a las exigencias éticas y políticas de la sociedad. Tras el fin de la República y el advenimiento del Imperio se inicia un proceso de distanciamiento progresivo del Derecho respecto de la Moral, que alcanzará su mayor intensidad en el Derecho justinianeo. El ius irá perdiendo sus referencias éticas y la lex, fuente emanada de las asambleas populares (los Comicios), será sustituida por los decretos o constituciones imperiales. El espacio perdido por la Moral como fundamento del Derecho pasará a ser ocupado por la Política, en la medida en que las normas jurídicas serán la expresión formal de la voluntad del poder. Las máximas de que la voluntad del príncipe tiene fuerza de ley («quod pricipi placuit legis habet vigorem», Digesto, 1, 4, 1): o de que el príncipe no está sometido a las leyes («legibus solutus», Digesto, 11, 3, 31), atestiguan esa decantación autoritaria del Derecho Romano (Schulz, 1946).

De forma paralela, aunque antitética, a ese proceso jurídico-institucional fue forjándose en la filosofía jurídica romana, por especial impulso del estoicismo y posteriormente del cristianismo, un movimiento moralizador del Derecho. El fundamento de esa tendencia arranca de un célebre fragmento de Cicerón, en el que se afirma que el fundamento del Derecho no radica en el edicto del pretor, ni en las leyes de las Doce Tablas, sino que dimana «ex intima Philosophia» (De Legibus, I, 5). El fundamento filosófico del Derecho se contiene en la ley natural, síntesis de la normatividad moral y jurídica, que deriva de la recta razón, es conforme a la naturaleza y se halla presente en todos los hombres (De Legibus, I, 6; De República, III, 22). La doctrina estólea popularizada por Cicerón halló amplio eco en el pensamiento cristiano y se prolongó en el mundo medieval. Al propio tiempo, las nociones cristianas de pietas y charitas van penetrando en el Derecho Romano como una exigencia moralizadora de sus instituciones y de su interpretación (Biondi 1953; Roberti, 1935). Quizás la consecuencia más relevante de esa moralización de la experiencia jurídica y política romana postclásica, debida al influjo estoico y cristiano, sea el desplazamiento del término ius y su sustitución por la palabra «directum». Este será el germen etimológico de la expresión moderna del Derecho en las lenguas románicas, germánicas e inglesa. A partir del entonces se establece una distinción entre «directum», que de su significación inicial como adjetivo pasa a ser un sustantivo que designa las normas jurídicas «rectas», es decir, conformes a las exigencias morales estoico/cristianas; y el 
«ius», en cuanto Derecho estricto y rígido ajeno a cualquier connotación axiológica (Cesarini-Sforza, 1930, 38 ss.; Cruz, 1971,20 ss.).

\section{Cuatro modelos de articulación de las relaciones entre Derecho, Moral y Política}

Apenas bosquejada la aproximación histórica, con la plena consciencia de haber sólo enunciado un tema sobre el que queda casi todo por decir, las urgencias del presente apremian a plantear el actual status quaestionis de las relaciones entre Derecho, Moral y Política. Esta problemática, lo mismo en los hechos que en las doctrinas, resulta inabarcable y por ello habré de limitar esta nota a seleccionar cuatro modelos explicativos que, en cierto modo, pueden contribuir a compendiar un panorama muy vasto y complejo.

\subsection{Primer modelo: separación radical}

Este modelo hace referencia a los empeños teóricos dirigidos a establecer una nítida línea divisoria entre el Derecho, la Moral y la Política, así como entre las disciplinas que tienen por objeto su respectiva elaboración teórica. Para ejemplificar esta actitud pudiera servir de referencia la imagen de las líneas paralelas que nunca se encuentran, ni entrecruzan (Fig. 1). Según este planteamiento Derecho, Moral y Política son tres órdenes normativos autónomos, entre los que no tiene porqué existir interferencias; sino que cada uno de ellos responde a una lógica propia y distinta que regula, asimismo, sectores de la conducta humana diversos e independientes. El positivismo jurídico radical constituye el principal marco teórico explicativo y propugnador de esta tesis.

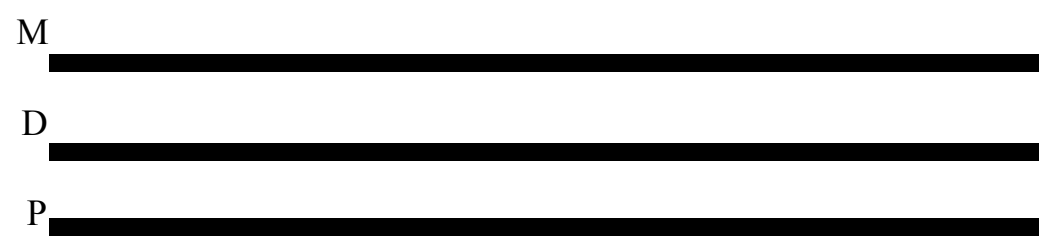

Sin resquicio a dudas Hans Kelsen puede ser considerado el pensador más representativo de esta actitud. La idea de «pureza» es el elemento que, según Kelsen diferencia su doctrina de las demás Teorías del Derecho. Para Kelsen la Teoría del Derecho debe tomar 
como objeto de estudio al Derecho en sí, es decir al Derecho en cuanto estructura normativa autosuficiente, autorreferente y coherente. Para individualizar lo que diferencia al Derecho de la realidad, Kelsen se remite a la distinción kantiana entre «ser» y «deber ser», situando al Derecho y a la Ciencia jurídica en el ámbito del «deber ser». Kelsen advierte al propio tiempo, que ese «deber ser» es de naturaleza lógica y formal-normativa, no se trata, por tanto, de un «deber ser» ético. A tenor de las premisas kelsenianas sobre el carácter autónomo («puro») de la Ciencia jurídica un concepto ético, político o sociológico del Derecho, resulta científicamente tan inadecuado como un concepto médico de la Arquitectura, o un concepto económico de la Química.

A juicio de Kelsen, con el término «fuente del Derecho» se pueden entender todos los medios de producción jurídica y también el fundamento de la validez, en particular, el fundamento último de la validez de un ordenamiento jurídico; esto es, la norma fundamental. Pero, de hecho, -señala Kelsen- se define como «fuente» sólo el fundamento de Derecho positivo de la validez de una norma jurídica, o sea la norma jurídica superior que regula la producción. En este sentido, la Constitución es la fuente de las normas jurídicas generales producidas mediante la legislación y la costumbre; y una norma jurídica general es fuente de la sentencia judicial que constituye una norma individual por la que se aplica la general; pero la sentencia, a su vez, puede ser considerada fuente de los derechos y deberes de las partes en litigio (los cuales se fundan en ella) o de la autorización al órgano que debe ejecutar dicha sentencia. En este sentido jurídico-positivo, concluye Kelsen, fuente del Derecho sólo puede ser el Derecho: (In einem positiven rechtlichen Sinn kann Quelle des Rechts nur Recht sein). Cuando con la expresión «fuente» se alude a los distintos factores que, de hecho, influyen en la producción y aplicación del Derecho, principios morales y políticos, teorías jurídicas, opiniones doctrinales, etc. se emplea el término en su sentido no jurídico. En efecto, según Kelsen, mientras las fuentes jurídicas son siempre directamente vinculantes, las no jurídicas no lo son hasta que una forma jurídica positiva no las reconoce como fuentes del Derecho; es decir, hasta que las hace vinculantes (Kelsen, 1960, 238 ss.).

En su póstuma Allgemeine Theorie der Normen, Kelsen ha reformulado su concepto de la norma fundamental (Grundnorm) en cuanto principio de validez del sistema de fuentes jurídicas. Dicha norma que, en la segunda edición de la Reine Rechtslehre, era considerada como una norma presupuesta (vorausgesetz), pasa ahora a ser entendida como una norma ficticia. Kelsen mantiene su tesis, expuesta en sus obras anteriores, de que el fundamento de validez de una norma no puede ser más que otra norma, y que para evitar el regressus in 
infinitum hay que partir de una norma fundamental, entendida como norma suprema del ordenamiento de la que todas las restantes reciben su validez. La unidad, jerarquía, plenitud y coherencia del sistema de fuentes jurídicas no reposa en ningún elemento fáctico (personas, instituciones, o contenidos normativos), sino en un criterio rigurosamente «puro»; es decir, formal. Pero, en su obra póstuma, señala que la (Grundnorm) no es una norma positiva, sino una norma meramente pensada, o sea, una ficción. Kelsen se remite expresamente a la filosofía del «como si» (die Philosophie des Als-Ob) de Hans Vaihinger para explicar el alcance ficticio de la norma fundamental. En función de las premisas de la filosofía del «como si», la Grundnorm entraña una ficción «propia» o auténtica ya que implica, a la vez, una contradicción externa con la realidad y una contradicción interna consigo misma. Así, la norma fundamental de un ordenamiento jurídico: «Hay que actuar como prescribe la primera Constitución histórica», no sólo contradice la realidad, ya que no existe una norma tal como sentido de un acto de voluntad real; si no también es contradictoria en sí misma, porque representa la autorización de una suprema autoridad jurídica y, por tanto, procede de una autoridad, aunque ficticia, superior a ella. Hans Kelsen, advierte además, que el significado de la norma fundamental como ficción difiere de su consideración como hipótesis, tal como él mismo la había definido en etapas anteriores; pues la ficción se diferencia de la hipótesis en que implica, o debe implicar, la consciencia de su falta de correspondencia a la realidad (Kelsen, 1979, 206 ss.).

La impecable elaboración epistemológica de la teoría de las fuentes kelseniana suscita, no obstante, consideraciones críticas externas e internas. Desde el punto de vista intrasistemático resulta contradictorio respecto a los propios presupuestos teóricos de la teoría pura del Derecho, que la norma fundamentadora del sistema de fuentes jurídicas no sea una norma puesta, es decir, positiva. La Grundnorm no es una norma que forme parte del ordenamiento positivo, por tanto, no es una norma jurídica en la acepción kelseniana, sino una mera ficción. El estricto monismo y la pureza (Reinheit) de la tesis de Kelsen resultan seriamente comprometidos por la remisión a un criterio fundamentador de la validez, un postulado ficticio en el sentido de la filosofía del $A l s-O b$, ajeno al sistema normativo positivo. En el plano externo, no menos dosis de perplejidad suscita el que Kelsen propugne, al mismo tiempo, la tajante separación entre Derecho, Moral y Política y la identificación entre Derecho y Estado. Es cierto que para Kelsen el dualismo Derecho-Estado desaparece en la medida en que el Estado se concibe sólo como un «orden normativo»; pero, pese a ello, una concepción no política de Estado, 
supone una elucubración tan contradictoria como la de una concepción no jurídica del Derecho.

\subsection{Segundo modelo: separación relativa}

El sentido demasiado restricto de la tesis que defiende una separación absoluta entre Derecho, Moral y Política, así como las dificultades para ofrecer una explicación satisfactoria de los insoslayables encuentros de estos sectores normativos de la vida práctica, han determinado la aparición de tesis que propugnan mitigar la radicalidad de la fisura entre ellos. Desde estos enfoques no se abandona la tesis de la autonomía e independencia conceptual de cada una de estas tres formas de normatividad, pero se reconocen determinados puntos de conexión e interferencia. A tenor del modelo de la separación relativa, la relación entre Derecho, Moral y Política puede simbolizarse bajo la forma de una pirámide en cuya cúspide aparece la Moral (el mínimo ético) como criterio legitimador del Derecho que a su vez actúa como orden normativo encauzador de la actividad política (Fig. 2). Pero, al margen de esos puntos de conexión, cada uno de los tres sectores es un compartimento independiente, que conserva su autonomía conceptual y funcional.

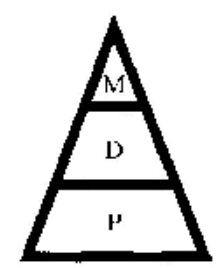

Fíg. 2

En el plano teórico este modelo conecta con los postulados del positivismo político moderado, el cual no desconoce la fundamentación última del Derecho en un mínimo ético, si bien por razones metodológicas y de seguridad jurídica mantiene la exigencia de no confundir el Derecho que «existe» (Derecho positivo), del que moralmente se aspira que «debiera existir» (Derecho natural). Asimismo, sin reconducir la normatividad jurídica al ámbito de los hechos sociales y políticos, tienden a evitar las ficciones formalistas al admitir un soporte político de las normas como garantía de su eficacia. 
No estimo que se juzgue aventurada la hipótesis de considerar a Herbert Hart como el más representativo defensor de este modelo teórico. La concepción teórico jurídica de Herbert Hart, considerada como una de las más valiosas e influyentes revisiones de la doctrina kelseniana, tiene uno de sus insoslayables nudos temáticos y problemáticos en las relaciones de la Moral con el Derecho y la Política. Al formalismo estricto kelseniano, que hace reposar la validez del sistema de fuentes en una Grundnorm ficticia, opone Hart una «regla de reconocimiento» (rule of recognition) que posee una incuestionable dimensión empírica en cuanto responde a la actividad jurídica efectiva de los órganos públicos y de los ciudadanos. La regla de reconocimiento raramente se halla establecida, ni es un mero presupuesto lógico-trascendental o ficticio, sino que su existencia se revela (is shown) en la práctica social, en la medida en que los funcionarios, en particular los jueces, y los ciudadanos atribuyen validez a un determinado sistema de normas (Hart, 1961, 97 ss.).

Resulta obligado recordar en este punto que la teoría de Hart defiende y formula un contenido mínimo del Derecho natural. Lo integrarían un conjunto de verdades obvias (rasgos antropológicos que definen la naturaleza de los seres humanos: su vulnerabilidad. igualdad aproximada, limitación de su altruismo, capacidad intelectual y fuerza de voluntad, así como la propia limitación de los recursos) que deben ser tomadas en consideración para garantizar la supervivencia humana y la propia viabilidad de las sociedades. Si las instituciones sociales no quieren ser simples clubs de suicidas tendrán que admitir reglas que, haciéndose cargo de la naturaleza del hombre y del mundo, impidan la violencia, regulen la propiedad y organicen, en suma, la cooperación social a través de normas coercitivas. Todo ello, muestra que el Derecho y la Moral no pueden explicarse en términos puramente formales, sin hacer referencia a contenidos o a necesidades sociales (Hart, 1961, 189 ss). Estas ideas se hallan corroboradas en la doctrina hartiana sobre los derechos humanos. Respecto a ella admite Hart que existe un derecho natural universal, que se traduce en el derecho igual de todos los hombres a ser libres (Hart, 1962, 65 ss). En estudios posteriores ha calificado de «absurdo» el rechazo de que puedan existir derechos humanos o naturales que no procedan del Derecho positivo (Hart, 1980; 1982). Hart ha llegado a sostener que «lo que se necesita para dar sentido a la noción de los derechos morales universales es una teoría de lo que necesitan los individuos y de lo que pueden exigir razonablemente de cada uno (mediante constricción o provisión activa) para perseguir sus propios fines mediante el desarrollo de las diversas facultades humanas»(Hart, 1984-5, 161).

Herbert Hart, en su sugerente análisis del deber jurídico, partía de la diferencia entre el deber de obedecer la conminación de un bandido 
y el deber de obedecer a la norma jurídica del Estado. Advierte el propio Hart, que la explicación del Derecho no puede hacerse en términos puramente formales, sino tenido presente sus contenidos. Luego parece que la distinción entre la obligación que impone el bandido y la que dimana de la norma jurídica, no puede cifrarse sólo en la procedencia formal de las respectivas obligaciones. Máxime si se tiene presente, y aquí parece oportuno hacerlo, la célebre y nunca obsoleta advertencia agustiniana de que, cuando se apartan de la justicia, los reinos se convierten en grandes bandas de bandidos (De civitate Dei, IV, 4). A partir de la regla de reconocimiento, Hart pretende superar las concepciones empíricas (coactivas) del deber jurídico. Pero sería erróneo pensar que dicha regla tiene un significado puramante formal-normativo, porque recibe su contenido de la práctica social. No hay norma de reconocimiento sin aceptación social de su contenido, al menos por parte de los funcionarios. Esa aceptación no puede dejar de hacer referencia a los valores morales de una comunidad social. De ahí que, a la postre, el fundamento del orden jurídico se cifre en una determinada forma de compromiso moral (Cfr. Pérez Luño, 1991c, 381 ss.).

\subsection{Tercer modelo: integración absoluta}

La reminiscencia del ethos, así como el ideal de un orden jurídico y una vida política sustentados sobre la Moral han conducido a teóricos de ayer y de hoy a reclamar la estricta integración de los tres ámbitos normativos de la conducta práctica. Desde estas premisas, que pueden formalizarse en la figura de los círculos concéntricos (Fig. 3), la Moral posee un significado omnicomprensivo abarcador de las demás normatividades. A su vez, el Derecho debería ser la pauta reglamentadora de la vida política. Ha adquirido celebridad la advertencia agustiniana de que no parece posible admitir la existencia de una ley que no sea justa (De libero arbitrio, I, 5, 11), glosada en la no menos célebre sentencia tomista de que la ley positiva contraria al Derecho natural no es ley, sino corrupción de la ley (legis corruptio) (Summa theologiae, I, II., q.95.a.2).

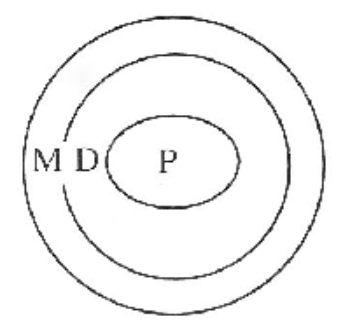


Esta tesis ha hallado eco en el iusnaturalismo neotomista, así como en otras doctrinas iusnaturalistas de la cultura contemporánea. Suele ser un rasgo distintivo común a las diversas teorías neotomistas la convicción de que la ontología jurídica, al indagar el ser del Derecho en su significación plenaria, desemboca forzosamente en la deontología; es decir, en el «deber ser» jurídico. Por ello, desde la perspectiva de la estructura ontológica del Derecho, el Derecho natural, entendido como Derecho objetivo justo, se identifica con la noción misma del Derecho; es más, a tenor de este planteamiento, la propia noción de Derecho justo constituye un pleonasmo, ya que pueden existir leyes injustas, pero no un Derecho injusto. Se han invertido así los términos en que, desde un prisma rigurosamente iuspositivista, Bergbohm había aludido a la cuestión, al afirmar que el empleo del adjetivo positivo para la calificación del Derecho no era más que un pleonasmo, dada la imposibilidad de concebir un Derecho que no fuera positivo. En las antípodas de ese enfoque, los iusnaturalistas radicales piensan que si bien pertenece al concepto de Derecho justo el ser positivo, es también cometido del Derecho positivo el ser sustancialmente justo, si se considera que el Derecho positivo tan sólo puede tener validez a través de su participación en la justicia que, a su vez, compendia la dimensión jurídica de la Moral (Cfr. Pérez Luño, 1971, 119 ss.; 1992, 59 ss. y 67 ss.).

Han adquirido también notoriedad, en la cultura jurídica de la segunda mitad de nuestro siglo, las tesis del último Radbruch en las que propugna un iusnaturalismo radical integrador de la Política y el Derecho en la Moral. Gustav Radbruch indica: «No se puede definir el Derecho, incluso el Derecho positivo, si no es diciendo que es un orden establecido con el sentido de servir a la justicia. Aplicándoles este patrón, hay partes enteras del Derecho nacionalsocialista que nunca llegaron a tener la categoría de Derecho valido» (Radbruch, 1971, 14). Radbruch consideraba al Derecho natural, en cuanto encarnación de los valores éticos de la justicia, como «un Derecho superior a la ley, supralegal, aquel rasero con el que medir las mismas leyes positivas y considerarlas como actos contrarios a Derecho, como desafueros bajo forma legal» (Radbruch, 1965, 180).

\subsection{Cuarto modelo: integración relativa}

El iusnaturalismo radical ha tropezado siempre con el escollo que supone negar la condición de Derecho a las legislaciones históricas que no responden a determinados criterios de justicia. El absolutismo que implica esta tesis se prolonga en una concepción, a su vez, absolutista y objetivista de los valores. Esta postura tiene a su favor 
su rechazo del relativismo y el escepticismo axiológicos; pero en su contra hay que advertir que propugna un orden ontológico, cerrado y ahistórico de valores metafísicos, eternos e inmutables. De ahí se deriva el riesgo de que un sector de la sociedad, sintiéndose intérprete y portavoz de ese orden axiológico objetivo, trate de imponer una «tiranía de valores» a los demás; lo que es abiertamente incompatible con un sistema ético, jurídico y político pluralista.

El modelo de integración relativa, que corresponde a las posturas del iusnaturalismo moderado, rechaza lo mismo las tesis que propugnan la separación entre Derecho, Moral y Política, especialmente en su versión fuerte, que la que postula su total integración. Frente a ambos enfoques defiende la autonomía e independencia relativa de Derecho, Moral y Política en determinados aspectos, y su coincidencia necesaria en otros. Su representación gráfica responde a los círculos secantes, cuya intersección representa el espacio, más o menos amplio según las distintas tesis doctrinales, del encuentro y conexión entre Derecho, Moral y Política (Fig. 4).

En la hora presente se puede considerar como una postura representativa de este planteamiento a la de Ronald Dworkin. Dworkin tiende a evidenciar el carácter fragmentario e insatisfactorio de las tesis que hacen reposar la validez del sistema de fuentes en criterios formales normativos, a partir de ello se haría depender la validez de las normas concretas de su conformidad con las normas de procedimiento que en cada ordenamiento jurídico regulan la producción jurídica (teoría que es calificada por Dworkin como test del pedigree) (Dworkin, 1978, 17 y 39 ss.). No menos rechazable le parecen las doctrinas que reconducen la validez al dato puramente fáctico de la eficacia de las normas, es decir, al hecho de su aplicación y cumplimiento mediante una determinada práctica social. El rechazo de cada una de estas posturas le conduce también al rechazo del sincretismo de ambas, tal como se desprendería de las tesis de Hart.

En la teoría del Derecho, que se desprende del pensamiento de Dworkin, ocupan un lugar privilegiado los principios. Puede, incluso, afirmarse que su revalorización de los principios constituye uno de los rasgos básicos de su construcción doctrinal y seguramente aquel que ha contribuido, en mayor medida, a la amplia difusión, pero también a la no menos amplia polémica, suscitada por sus escritos. Según la notoria tesis de Dworkin, todo ordenamiento jurídico se halla integrado por un conjunto de principios (principles), medidas o programas políticos (policies) y reglas o disposiciones específicas (rules). Dworkin denomina medidas políticas a las normas genéricas (standards) que establecen fines que deben alcanzarse y que implican un avance en el terreno económico, político o social 
para la comunidad; mientras que reserva la denominación de principios a los standards o prescripciones genéricas que entrañan un imperativo de justicia, de imparcialidad, o de cualquier otra dimensión de la moralidad. Son los principios, en cuanto entrañan los fundamentos morales del orden jurídico y la expresión de los derechos básicos de los ciudadanos, los que aseguran la coherencia y plenitud del sistema de normas que hace posible el imperio del Derecho (Dworkin, 1987, 22 ss.; 39 ss. y 71 ss.; 1985, 33 ss. y 72 ss.: 1986, 179 ss.; 213 ss. y 404 ss.).

De los argumentos expuestos, y de otros que pudieran aducirse en consideración más demorada en pormenores, se desprende mi convicción de que la teoría de Dworkin Derecho responde a un planteamiento iusnaturalista moderado. El tema del iusnaturalismo de Dworkin ha originado un amplio debate doctrinal (Cfr. Pérez Luño, 1993, 49 ss.). Ronald Dworkin ha admitido expresamente, en su ensayo Natural Law Revisited, que si por iusnaturalismo se entiende la teoría que postula que el contenido del Derecho depende, en ocasiones, de la respuesta correcta a alguna exigencias morales, entonces su teoría es iusnaturalista (Dworkin, 1982, 165). No obstante, al replicar a sus críticos y, de modo especial, en su Law's Empire, ha intentado desmarcarse de esa posición. Dworkin pretende situar su alternativa al positivismo jurídico en un plano distinto de las teorías del Derecho natural. Las diferencias de su posición respecto de éstas se cifrarían en dos aspectos fundamentales: 1) Las tesis iusnaturalistas entrañan una visión ideal y abstracta del Derecho, mientras que para Dworkin el Derecho y sus valores se sitúan en el plano de la práctica jurídica. 2) Las teorías iusnaturalistas establecen requisitos universales del Derecho y, a partir de ellos, niegan el carácter de Derecho a los ordenamientos positivos que no los cumplen. Frente a ellas, las teorías interpretativas serían aquellas que -en opinión de Dworkin- ofrecen marcos explicativos contextualizados, dirigidos a dar cuenta del Derecho en un ámbito jurídico determinado. La teoría de Dworkin es interpretativa, en el sentido de que está dirigida a explicar una cultura jurídica en particular: la anglo-americana. Desde esas premisas interpretativas no se niega, por ejemplo, que los nazis tuvieran Derecho, a pesar de que fuera muy injusto. La teoría interpretativa exige la vinculación del Derecho a valores morales en aquellas culturas jurídicas inspiradas en esa exigencia, pero no niega la condición de Derecho a los sistemas políticos manifiestamente inmorales que respondan a otras culturas jurídicas (Dworkin, 1986, 101 ss.).

Quizás pudiera juzgarse inoportuno este esfuerzo encaminado a mostrar la adscripción de Dworkin al iusnaturalismo. No es ocioso recordar que el propio Dworkin ha mostrado sus reservas sobre la afición de los filósofos del Derecho a etiquetar las teorías ajenas y 
las propias; tarea que le parece de cuestionable utilidad (Dworkin, 1982, 165 s.). Pero si se examina la obra de Dworkin en su conjunto se advierte que pocas construcciones teóricas han sido tan dadas a utilizar e innovar categorías, clasificaciones y etiquetas como la de Dworkin. Dworkin no se siente a gusto con las etiquetas heredadas del pasado. Por eso prefiere sustituir los tradicionales modelos teóricos del iusnaturalismo, positivismo, realismo, formalismo, fenomenologismo, idealismo, institucionalismo..., por etiquetas nuevas tales como: el convencionalismo, el pragmatismo jurídico, las teorías semánticas, las teorías interpretativas o la teoría de la integridad. En ocasiones, las distinciones entre algunas de estas etiquetas resultan sutiles y sofisticadas. Baste observar su digresión teórica para distinguir el convencionalismo de las teorías semánticas. En otras ocasiones, Dworkin recurre a distinciones y subdistinciones constantes que no contribuyen a clarificar la estructura argumentativa de su discurso. Así, por ejemplo, cuando introduce la distinción entre integridad inclusiva e integridad pura, en las últimas páginas de su Law's Empire, lo que obliga a una relectura de la obra para discernir a cuál de estos dos sentidos se están refiriendo sus constantes apelaciones a la teoría de la integridad contenidas en ella.

El balance compendiado de los cuatro modelos expuestos muestra que sólo uno de ellos supone una separación radical entre Derecho, Moral y Política. Las otras tres posturas indican una diferencia más cuantitativa que cualitativa en el enfoque de esa relación. Así, respecto a la conexión total que se desprende de la tesis integracionista radical, las versiones moderadas de la separación y la integración entrañan diferencias muy sutiles, en ocasiones, de puro matiz. Quizá el rasgo decisivo para diferenciar ambas posturas moderadas resida en que en la primera, la fundamentación moral del orden jurídico y político queda circunscrita a la cúspide de la pirámide normativa. A tenor de este modelo el Derecho y la Política son órdenes normativos plenamente autónomos excepto en lo que atañe a su legitimidad última. Se trata, en otros términos, de un modelo de legitimidad concentrada. Mientras que el integracionismo moderado representa un modelo de legitimación difusa, que defiende la existencia de un determinado sector de coincidencia y coimplicación necesaria (por ejemplo, todo el que atañe a la normatividad jurídica de valores y principios) entre el Derecho, la Moral y la Política.

\section{Derecho, Moral y Política: distanciamientos y aproximaciones actuales}

Suelen oponerse, siempre a favor de la primera, la calidad a la cantidad, pero hay obras a las que se les agradece la segunda, la larga 
y generosa extensión. Tal es el caso de la obra monumental, en volumen y enjundia, dedicada por Ernesto Garzón Valdés a tratar de Derecho, Ética y Política. Constituye este libro un síntoma ejemplar de la multiplicidad de cuestiones y problemas que hoy se debaten en las innumerables encrucijadas que señalan las tensiones entre Derecho, Moral y Política. En las primeras páginas del libro se lee: «La abstención de interdisciplinariedad, que durante la primera mitad del siglo XX caracterizara la actividad de una buena parte de los más distinguidos teóricos y filósofos del Derecho, parece ir cediendo terreno frente a una cada vez más estrecha relación entre el Derecho, la Ética y la Filosofía política» (Garzón, 1993, 12). Se compendia así un estado de opinión prevalente en la cultura contemporánea tendente a reforzar los vínculos entre las normatividades de la vida práctica (Cfr., entre otros, los trabajos de: Alexy, 1989-, Díaz, 1990; Dreier, 1981; Fernández, 1990; Habermas, 1992...). Sería un error concebir esta tendencia como un mero punto de inflexión casual de posturas teóricas orientadas hacia los modelos integrativos frente a las tesis separatistas. Porque enseña un célebre motto de Hegel que la filosofía, y ello es predicable de las demás teorías doctrinales, debe ser «La aprehensión de su tiempo en pensamientos» (Grundlinien der Philosophie des Rechts, Vorrede).

Interpretando los signos del tiempo, Erhard Denninger, en un sugerente ensayo, señala como uno de los rasgos caracterizadores de la actual coyuntura jurídica y política alemana la tendencia hacia la moralización del orden constitucional. Según Denninger ello supone la expresión «de una nueva tendencia a desformalizar el Derecho y a propiciar una nueva síntesis de los principios del Derecho con los valores morales» (Denninger, 1994, 71). En su análisis ofrece algunos testimonios relevantes de este proceso. En ellos se advierte una pretensión de moralizar el Derecho constitucional que va más allá de la recepción de determinados valores éticos ampliamente reiterados en el constitucionalismo comparado (dignidad, libertad, autonomía, igualdad, autodeterminación...). Así, por ejemplo, recuerda que la tutela ecológica viene ampliada hasta abarcar la responsabilidad hacia las generaciones futuras lo que entraña una novedad del sistema jurídico (art. 10.1 de la Constitución de Sajonia; art. 39.1 de la Constitución de Brandeburgo). Plena de problemas sociales se halla la promesa del artículo 22.2 de la Constitución de Sajonia, que prescribe: «Quien críe y eduque niños o cuide a menesterosos, enfermos o ancianos, merece promoción y ayuda». Así mismo refleja este tipo de inquietudes el artículo 26.3 de la Constitución de Brandeburgo cuando establece: «Quien en un matrimonio, en una familia o en otra comunidad de vida sufra violencia psíquica o física, tiene derecho a la asistencia y tutela de la colectividad». Incluso un diputado de la 
antigua Alemania Oriental ha propuesto la introducción en el futuro texto de la Constitución Federal de Alemania de la formula siguiente: «La veracidad promueve un mejor entendimiento entre los hombres» (Denninger, 1994, 70 ss.).

Ante estos empeños moralizadores del sistema constitucional resulta inevitable la evocación del entusiasmo ético ilusorio y voluntarista que delataba el célebre artículo 6 de nuestra Constitución gaditana de 1812, que prescribía como obligación de todos los españoles «ser justos y benéficos», así como«el amor de la patria»; obligación de amar que recuerda, por antítesis a La prohibición de amar (Das Liebesverbot), que da título a una ópera menor de Richard Wagner. Obligaciones que parecen ignorar la naturaleza incoercible del amor.

A los efectos de esta reflexión importa destacar el dilema que se desprende de este tipo de formulaciones. Porque si se atiende precipitada e indiscriminadamente a todas las demandas éticas que hoy pugnan por inscribirse en las normas constitucionales, se corre el riesgo de olvidar que estas normas son y deben seguir siendo «Constituciones de juristas y no de sacerdotes» (Denninger, 1994, 70), y, en suma pueden hacer peligrar las garantías de la seguridad jurídica que son irrenunciables en un Estado de Derecho (Pérez Luño, 1994, 61 ss.). Si, por el contrario, se rechazan estas tendencias moralizadoras del Derecho y de la Política se estarán desatendiendo algunas de las demandas más urgentes de las sociedades actuales. El fenómeno ominoso de la corrupción de la vida política, que está afectando al funcionamiento de instituciones básicas de los Estados de Derecho; la proliferación de mafias de distinto signo que envilecen los procesos sociales, políticos y económicos; el alarmante déficit de solidaridad que reflejan determinadas actitudes racistas y xenófobas y la consiguiente necesidad de superar actitudes discriminatorias entre los hombres y los pueblos, exigen un consenso moral multinacional y multicultural, o, si se quiere, la conformación de un ethos universalista.

La tarea de ofrecer un enfoque adecuado a ese dilema constituye uno de los grandes retos de la cultura humanista contemporánea. A modo ejemplar, reseñaré algunos planteamientos significativos de la hora presente. En determinadas contribuciones se ha recordado que el proyecto ilustrado de la modernidad que desemboca en el Estado de Derecho tiene como soporte el paradigma racional de la conexión entre Derecho, Moral y Política. De ahí, que: «la pérdida de los valores morales que son la «última ratio» de este modelo y su sustitución por ese «realismo» del éxito inmediato que afecta a pilares tan básicos, conduce a la arrogancia, y a unos ideales economicistas, egoístas y aislacionistas, que sólo fomentan la emulación y el bienestar, y que pueden convertirnos en un simple lugar para el consumo» (Peces-Barba, 1993, 45). 
Pero de esas advertencias no se deben inferir conclusiones precipitadas e ilusorias sobre los beneficios de una moralización del Derecho a cualquier precio. Tiene razón Francisco Laporta cuando nos insta a «caer inmediatamente en la cuenta de que la incorporación de contenidos morales a las normas jurídicas no siempre es deseable, quizá ni siquiera moralmente deseable» (Laporta 1993, 100). Las cruzadas en favor del «rearme moral de la sociedad a través del Derecho» no están exentas de riesgos. He advertido, en algunos trabajos, del peligro de dogmatismos que implica el que el Derecho apele a categorías morales sedicentemente universales e inmutables. Por ese camino se corre el riesgo de hipostasiar como principios de moralidad válidos semper et ubique lo que no son sino el sistema de creencias e intereses de quienes detentan el aparato jurídico y político. El Derecho de una sociedad pluralista no puede servir de instrumento para someter a una determinada concepción moral todas las restantes. Para ello deberá evitarse una injerencia de la normatividad jurídica en aquellos comportamientos morales que no afecten o perjudiquen a terceros. Ahora bien, el rechazar las amenazas, en orden al pluralismo y la libertad, de una concepción absolutista y dogmática de la moral, en la que los valores éticos que influyen o informan la experiencia jurídica, so pretexto de su universalidad e inmutabilidad, son en la práctica el fruto de una intuición arbitraria y decisionista que suele degenerar en una auténtica tiranía de los valores (Thyrannei der Werte), no debe precipitarnos en el otro polo o cara de la moneda. Es decir, no menos inquietante resulta la alternativa opuesta de un total relativismo ético conducente al nihilismo y la abstinencia de valores. Frente a ambas opciones he intentado, en otros trabajos, abogar por un intersubjetivismo axiológico cifrado en el reconocimiento de la posibilidad de que la razón práctica llegue a un consenso, abierto y revisable, sobre el fundamento de los valores ético-jurídicos. Consenso que, por otra parte, lejos de traducirse en fórmulas abstractas y vacías, recibe su contenido material del sistema de necesidades básicas o radicales que constituyen su soporte antropológico (Pérez Luño, 1990, 329 ss.; 1991a, 176 ss. y 298 ss.; 1991b, 83 ss.).

Otro demérito de algunos de los actuales empeños moralizadores del Derecho y la Política es el de promover un tipo de argumentaciones voluntaristas, puramente ideales y abstractas, desligadas de la experiencia. Está en lo cierto Elías Díaz cuando advierte que: «en cualquier ámbito o marco de actuación, pretender regular la fuerza sin tener a su vez fuerza puede resultar algo incluso edificante y meritorio, pero también patético y, en ciertas malas condiciones, hasta ridículo» (Díaz, 1993, 212).

En definitiva, el postulado del positivismo jurídico sobre la separación 
entre Moral y Derecho, pese a sus eventuales ventajas en el plano metodológico, resulta irrealizable en el práctico. Ello se debe a la coimplicación de factores éticos e ideológicos en el desenvolvimiento de la experiencia jurídica. Pero, reconocer esto, no supone afirmar que la tesis iusnaturalista de la continuidad entre Política, Moral y Derecho constituya en sí misma una respuesta satisfactoria de esta problemática. Aceptar la remisión recíproca entre Política, Moral y Derecho no entraña la solución de nada, sino más bien el planteamiento de todo. Por ello, la apertura del Derecho y la Política a la Moral no deber ser un cómodo expediente para suplantar el rigor en la formulación del razonamiento jurídico por categorías difusas y nebulosas que, bajo la apelación a la Moral, enmascaren las opciones ideológicas del legislador o del juez; ni tampoco para elucubraciones ideales de programas éticos-jurídicos insensibles a los presupuestos políticos que condicionan su realización.

$\mathrm{Al}$ recapitular estas reflexiones estimo relevante detectar como síntoma del presente la prevalencia de las tendencias centrípetas del ethos. El fenómeno en sí no parece objetable porque, como he tenido ocasión de apuntar, existe hoy una inquietud ampliamente compartida para que el orden jurídico y político se fundamente sobre un consenso de los valores morales que lo fundamentan. Esta observación no implica que las corrientes centrífugas hayan perdido toda su vigencia; les incumbe todavía un papel relevante para evitar síntesis apresuradas y confusas sobre los tres sectores normativos de la vida práctica. Especialmente inquietantes me parecen algunas versiones actuales del ethos, postuladas desde determinados enfoques comunitaristas, que lo conciben como una vuelta a las identidades colectivas nacionalistas o tribales. Frente a ellas, hoy más que nunca, se precisa una fundamentación de los sistemas jurídicos y políticos en un ethos universalista, síntesis de valores multinacionales y multiculturales; un ethos que haga posible la comunicación intersubjetiva, la solidaridad y la paz. No se trata de la expresión de meros buenos deseos teóricos. La articulación de la relaciones entre Derecho, Moral y Política, concierne a nuestra labor intelectual, pero también a nuestra entera vida cívica y al inquirir estas cuestiones no somos observadores externos porque, en definitiva, de nobis fabula narratur.

\section{BIBLIOGRAFÍA}

Alexy, R. (1989), «On necessary Relation between Law and Morality», en Ratio Jurris, nº 2, págs. 167-186.

Biondi, B. (1973), Arte y ciencia del Derecho, trad. cast. de A. Latorre, Ariel, Barcelona. 
Cesarini-Sforza, W. (1930), «Jus» e «directum». Note sull'origine storica dell'idea del diritto, Stabilimenti Poligrafici Riuniti, Bologna.

Cruz, S. (197 1), Ius. Derectum (Directum), Gráfica de Coimbra, Coimbra.

Denninger, E (1994), «La Reforma Constitucional en Alemania: entre Ética y Seguridad jurídica», trad. cast. de A. E. Pérez Luño, en Revista de Estudios Políticos, n. ${ }^{\circ}$ 84, págs. 69-78.

Díaz, E. (1990), Ética contra política. Los intelectuales y el poder, Centro de Estudios Constitucionales, Madrid.

Díaz, E. (1993), «El Derecho: la razón de la fuerza y la fuerza de la razón», en Derechos y Libertades, n. ${ }^{\circ}$, págs. 209-224.

Dreier, R. (1981), Recht-Moral-Ideologie, Suhrkamp, Frankfurt a. M.

Dworkin, R. (1978), Taking Rights Seriously, Duckworth, London, 2. ${ }^{\text {a }}$ ed. (existe trad. cast. de M. Guastavino, con Prólogo de A. Calsamiglia, Ariel, Barcelona, 1984).

Dworkin, R. (1982), «Natural Law Revisited», en University of Florida Law Review, vol. XXXIV, págs. 165 ss. (existe trad. cast. de S. Íñiguez, en el vol. a cargo de J. Betegón y J. R. de Páramo, Derecho y Moral. Ensayos analíticos, Ariel, Barcelona, 1990).

Dworkin, R. (1985), A Matter of Principle, Harvard University Press, Cambridge (Mass.) and London.

Dworkin, R. (1986), Law's Empire, Fontana, London, (existe trad. cast. de C. Ferrari, revisada por E. Abril, Gedisa, Barcelona, 1988).

Fassò, G. (1959), La democrazia in Grecia, Il Mulino, Bologna.

Fernández, E. (1990), Estudios de Ética Jurídica, Debate, Madrid.

Garzón Valdés, E. (1993), Derecho, Ética y Política. Centro de Estudios Constitucionales, Madrid.

Habermas, J. (1992), Faktizität und Geltung. Beitrüge zur Diskurstheorie des Rechts und des demokratischen Rechtsstaats, Suhrkamp, Frankfurt.

Hart, H. (1961), The Concept of Law, Clarendon Press, Oxford, (existe trad. cast. de G. R. Carrió, Abetedo-Perrot, Buenos Aires, 1963).

Hart, H. (1962 ), ¿Hay derechos naturales?, en su vol. Derecho moral. Contribución a su análisis, trad. cast. de G. R. Carrió, Depalina, Buenos Aires.

Hart, H. (1980), «Entre el principio de utilidad y los derechos humanos», trad. cast. de M. D. González Soler, F. Laporta y L. Hierro, en Revista de la Facultad de Derecho de la Universidad Complutense de Madrid. n. $^{\circ}$ 58, págs. 7-28.

Hart, H. (1982 ), «Utilitarismo y derechos naturales», trad. cast. de J. R. de Páramo, en Anuario de Derechos Humanos, n. ${ }^{\circ}$ 1. págs. 147-168.

Hart, H. (1984-85): «Derechos naturales: Bentham y John Stuart Mill», trad. cast. de J. R. de Páramo, en Anuario de Derecho Humanos. n. ${ }^{\circ}$ 3, págs. 137-162.

Kelsen. H. (1960), Reine Rechtslehre, Franz Deuticke, Wien, 2. (existe trad. cast. de R. Vernengo, UNAM, México, 1979).

Kelsen. H. (1979), Allgemeine Theorie der Normen, ed. a cargo de K. Ringhofer y R. Walter, Manzsche Verlag-und Universitätsbuchhandlung, Wien.

Laporta, F. (1993), Entre el Derecho y la Moral, Fontamara, Puebla (México). 
Ortega y Gasset, J. (1983), Teoría de Andalucía y otros ensayos, en Obras Completas, Alianza Editorial \& Revista de Occidente, Madrid, vol. 6.

Pérez Luño, A. E. (1971), Iusnaturalismo y positivismo jurídico en la Italia moderna, con Prólogo de Guido Fassò, Publicaciones del Real Colegio de España, Bolonia.

Pérez Luño, A. E. (1990), Recht, Moral und Politik: Zur Rechtsprechung des Obersten Gerichtshofs in Spanien während der Franco-Zeit, en el vol. col. Spanische Studien zur Rechstheorie und Rechtsphilosophie, a cargo de E. Garzón Valdés, Duncker \& Humblot, Berlín, págs. 329-341.

Pérez Luño, A. E. (1991a), Derechos humanos, Estado de Derecho y Constitución, Tecnos, Madrid; 4. ${ }^{\mathrm{a}}$ ed.

Pérez Luño, A. E. (1991b), ¿Qué moral? Sobre la justificación moral de la obediencia al Derecho, en «Sistema», n. ${ }^{\circ} 102$, págs. 83-97.

Pérez Luño, A. E. (1991c), ¿Qué deber? Consideraciones sobre el deber de obediencia al Derecho, con especial referencia a las tesis de H. L. A. Hart, en el vol. col. Obligatoriedad y Derecho. XII Jornadas de Filosofía Jurídica y Social (Oviedo, 28 al 30 de Marzo de 1990), Servicio de Publicaciones de la Universidad de Oviedo, págs. 381-406.

Pérez Luño, A. E. (1992), Lecciones de Filosofía del Derecho. Presupuestos para una filosofía de la experiencia jurídica, Minerva, Sevilla, $4{ }^{\mathrm{a}}$ ed.

Pérez Luño, A. E. (1993), El desbordamiento de las fuentes del Derecho, Real Academia Sevillana de Legislación y Jurisprudencia, Sevilla.

Pérez Luño, A. E. (1994), La seguridad jurídica, Ariel, Barcelona, 2. ${ }^{\text {a }}$ ed.

Radbruch, G. (1965), Introducción a la Filosofía del Derecho, trad. cast. de W. Roces, Fondo de Cultura Económica, México.

Radbruch, G. (1971), Leyes que no son Derecho y Derecho por encima de las leyes, en el vol. Derecho injusto y Derecho nulo, trad. cast. de J. M. Rodríguez Paniagua, Aguilar, Madrid.

Ritter, J. (1970), «Zur Grundlegung der praktischen Philosophie bei Aristoles» en Archiv für Rechts-und Sozialphilosophie, págs. 179-199.

Roberti, M. (1935), Cristianesimo e diritto romano, Vita e pensiero, Milano.

Schulz, F. (1946), History of the Roman Legal Science, Clarendon Press, Oxford.

Wolf, E. (1950-56), Griechisches Rechtsdenken, Klostermann, Frankfurt a. M. 4 vols.(De diversos capítulos de esta obra existe trad, cast. de E. Garón Valdés con el título de El origen de la ontología jurídica en el pensamiento griego, Universidad Nacional de Córdoba (Argentina), 1965, 2 vols.).

\section{$\Delta$

